\title{
Efeito de sistemas de consórcio e inseticida na formação dos estômatos em plântulas de erva-doce (Foeniculum vulgare Mill.)
}

\begin{abstract}
AZEVEDO, C.F. ${ }^{1 *}$; BRUNO, R.L.A. ${ }^{\text {; }}$ QUIRINO, Z.G.M. ${ }^{2}$; REGO, E.R. ${ }^{1}$; GOMES, K.R. ${ }^{1}$; BEZERRA, A.K.D. ${ }^{1}$
${ }^{1}$ Universidade Federal da Paraíba, Centro de Ciências Agrárias, Programa de Pós-graduação em Agronomia, Rodovia PB 097, Km 12, CEP: 58397-000, Areia-Brasil *camfiraze@bol.com.br ²Universidade Federal da Paraíba, Centro de Ciências Aplicadas e Educação, Departamento de Engenharia e Meio Ambiente, Sítio Engenho Novo, s/n, CEP: 58280-000, Mamanguape-Brasil
\end{abstract}

\begin{abstract}
RESUMO: Foeniculum vulgare Mill., pertencente à família Apiacea, é conhecida como erva-doce e apresenta grande importância medicinal e comercial, tanto no Brasil como em vários outros países. Objetivou-se com esta pesquisa, estudar o desenvolvimento dos estômatos em plântulas de $F$. vulgare oriundas de sementes produzidas em sistemas de consórcio erva-doce $X$ algodão e com aplicação do inseticida monocrotofós. A erva-doce foi cultivada em consórcio com algodão colorido cultivar BRS Safira, sendo utilizados os seguintes tratamentos: $1 \mathrm{~A} 2 \mathrm{E}$, uma fileira de algodão e duas de erva-doce; 2A1E, duas fileiras de algodão e uma de erva-doce; ES, erva-doce solteira; onde foram distribuídos com e sem aplicação de inseticida, totalizando seis tratamentos. As sementes colhidas foram semeadas em areia e mantidas em casa de vegetação por 25 dias. Partes das plântulas (zona de transição, caule, cotilédones e folhas) foram seccionadas à mão livre, coradas e montadas em lâminas com glicerina para observação em microscópio. Foram avaliadas as seguintes características: número de estômatos, diâmetro polar e equatorial dos estômatos e número de cloroplastos nas células-guarda. Os dados foram analisados em delineamento inteiramente casualizado e distribuídos em arranjo fatorial 3X2; sendo realizado teste de Tukey a $5 \%$ de probabilidade. Na zona de transição e no caule observou-se aumento do número e do diâmetro polar dos estômatos quando foram utilizados sistemas de consórcio. Nos cotilédones, a erva-doce solteira proporcionou maior número de estômatos, porém com menor diâmetro e com menor quantidade de cloroplastos. Já na folha, os consórcios influenciaram positivamente o número de estômatos e de cloroplastos. De forma geral, os sistemas de consórcio e o inseticida influenciaram positivamente o desenvolvimento dos estômatos das plântulas de erva-doce.
\end{abstract}

Palavras-chave: Apiaceae, cloroplastos, fotossíntese, germinação

ABSTRACT: Effects of intercropping systems and insecticide in formation of stomata in fennel seedlings. Foeniculum vulgare Mill., belonging to the family Apiaceae, is known as fennel and has great medicinal and commercial importance, both in Brazil and in several other countries. The objective of this research was to study the development of stomata of $F$. vulgare seedlings grown from seeds produced in intercropping systems fennel and cotton, with application of insecticide monocrotophos. The fennel was grown in association with colored cotton BRS Safira, with the following treatments: $1 \mathrm{~A} 2 \mathrm{E}$, one rows of cotton and two fennel; $2 \mathrm{~A} 1 \mathrm{E}$, two rows of cotton and one fennel; ES, fennel single; were distributed with and without application of insecticide, total six treatments. The seeds were sown in sand and kept in a greenhouse for 25 days. Parts of seedlings (transition zone, stem, cotyledons and leaves) were cut freehand, stained and mounted on slides with glycerol for observation under microscope. Were evaluated the following characteristics: stomata number, polar and equatorial diameter of the stomata and chloroplasts number in guard cells. The data were analyzed in completely randomized and distributed in factorial $3 \times 2$, being conducted Tukey test at $5 \%$ probability. The transition zone and stem showed an increase of the stomata number and polar diameter the when consortium systems were used. In cotyledons, fennel single provided the highest stomata number, but with smaller diameter and fewer chloroplasts. In leaf, the consortia have positively influenced the stomata and chloroplasts number. In general, the intercropping systems and insecticide positively influenced the development of stomata in fennel plants.

Key words: Apiaceae, chloroplasts, germination, photosynthesis

Recebido para publicação: setembro de 2011

Aceito para publicação: março de 2012

Rev. Bras. PI. Med., Botucatu, v.14, n.esp., p.205-213, 2012. 


\section{INTRODUÇÃO}

A erva-doce (Foeniculum vulgare Mill.) é uma cultura de grande importância medicinal e comercial, tanto no Brasil como em vários outros países, representando uma significativa fonte de renda para os agricultores.

Sistemas de consórcios têm sido utilizados para melhorar a qualidade das sementes de erva-doce (Nunes et al., 2007; Azevedo et al., 2009), com o intuito de promover alta capacidade fotossintética e consequentemente melhoria da produção. Segundo Altieri (2000) e Gliessman (2001), esses sistemas de produção também reduzem as perdas de produção decorrentes das irregularidades climáticas. Porém, esta espécie normalmente apresenta grandes infestações por pulgão (Lira \& Batista, 2006), o que induz a utilização de inseticidas. Tais produtos químicos podem ficar contidos nos tecidos vegetais, principalmente nas sementes e plantas jovens, influenciando a fisiologia, reprodução, metabolismo e crescimento (Chaboussou, 2006) e, possivelmente, ser passados para as gerações futuras. No entanto, pouco se sabe sobre a influência desses processos de produção sobre a estrutura da planta e principalmente, sobre os estômatos, que são responsáveis pela transpiração e pelo controle das trocas gasosas com o meio ambiente, influenciando diretamente a fotossíntese e consequentemente, como ressalta Silva et al. (2004), a produtividade vegetal.

Estudos de anatomia vegetal têm se constituído numa importante estratégia para determinar a qualidade de grandes culturas produzidas sob os mais diferentes sistemas, que visam aumentar o rendimento sem reduzir a qualidade (Moraes-Dallaqua et al., 2000; Santos et al., 2005; Leal-Costa et al., 2008). Pesquisas de morfoanatomia, especialmente com plântulas por estarem no período mais crítico da vida do vegetal (Crestana \& Beltrati, 1988), tentam mostrar os efeitos que o ambiente e os outros fatores bióticos e abióticos do meio exercem sobre esses indivíduos (Modesto et al., 1996; Bredemeier et al., 2001; Ceolin et al., 2007; Nery et al., 2007 ). Assim como trabalhos para observar a influência que agrotóxicos e insumos agrícolas exercem sobre a estrutura de várias espécies, que têm o intuito de verificar a toxicidade destes produtos sobre a fisiologia e o desenvolvimento dos vegetais (Martins \& Castro, 1999; Negrisoli et al., 2004; Castro et al., 2005).

Por esses motivos, é necessário observar como os sistemas consorciados e os produtos fitossanitários podem influenciar as características fisiológicas e anatômicas, especialmente a formação dos estômatos, tanto da própria planta tratada, como das futuras plântulas derivadas das sementes produzidas sob esses tratamentos.
Dessa forma, objetivou-se com esta pesquisa, estudar a formação dos estômatos de plântulas de $F$. vulgare oriundas de sementes produzidas em sistemas de consórcio erva-doce $X$ algodão e da aplicação do inseticida monocrotofós.

\section{MATERIAL E MÉTODO}

A pesquisa de campo foi conduzida na fazenda Boa Sorte, município de Montadas, na Paraíba, onde foram transplantadas mudas de ervadoce, cultivar Esperança, com 45 dias após a semeadura, em sistemas de consórcio com algodão colorido, cultivar BRS Safira. A preferência pelo algodão colorido neste experimento foi devido a este apresentar porte baixo, permitindo assim, a passagem de luz por entre os indivíduos e por já ter sido utilizado com sucesso em consórcio com outras culturas (Silva et al., 2007; Lima et al., 2008). Foram cultivadas linhas de $8 \mathrm{~m}$, com 0,80 m entre as fileiras e 0,30 m entre as plantas. A partir da terceira semana após o transplante das mudas, e durante dois meses foram feitas aplicações semanais de inseticida com princípio ativo monocrotofós.

No campo, o delineamento experimental adotado foi o inteiramente casualizado, em esquema fatorial $3 \times 2$, representados por três tratamentos de consórcio, com e sem aplicação de inseticida. Os seis tratamentos foram representados por: $1 \mathrm{~A} 2 \mathrm{E}$, uma fileira de algodão e duas fileiras de erva-doce; $2 \mathrm{~A} 1 \mathrm{E}$, duas fileiras de algodão e uma fileira de ervadoce; e ES, erva-doce solteira. Os três tratamentos foram distribuídos com e sem aplicação de inseticida, totalizando assim, 6 tratamentos. Na colheita dos frutos de erva-doce foram selecionadas cinco plantas ao acaso, de cada tratamento, nas quais tiveram todas as umbelas retiradas manualmente

A fase de laboratório foi realizada no Laboratório de Análise de Sementes do Centro de Ciências Agrárias (UFPB). Inicialmente, as sementes dos tratamentos selecionados foram retiradas das umbelas, beneficiadas e homogeneizadas. Foram semeadas 50 sementes de cada tratamento, a $1 \mathrm{~cm}$ de profundidade, em bandejas plásticas contendo 0 substrato areia umedecida.

As bandejas foram mantidas em casa de vegetação por 25 dias, sendo realizadas regas para a manutenção da umidade. Foram selecionadas plântulas normais e de padrão uniformes, com 25 dias, para as análises microscópicas e macroscópicas realizadas com material in vivo e conservado em álcool a $70 \%$. Foram avaliadas as seguintes características: número de estômatos, diâmetro polar e equatorial dos estômatos e número de cloroplastos nas célulasguarda.

Com o material selecionado, foram feitas 
secções paradérmicas a mão livre com lâmina de barbear. Foram utilizados, nas análises de algumas secções, hipoclorito de sódio a $1 \%$ e os corantes safranina a $10 \%$ e azul de metileno a $10 \%$. O material foi montado em lâminas semi-permanentes, com glicerina, e observado em fotomicroscópio.

A contagem dos estômatos foi realizada com lâmina milimetrada e os cloroplastos foram contabilizados fazendo-se uma média dos cloroplastos encontrados nas células-guarda de cinco estômatos. Todas as análises foram realizadas com quatro plântulas, onde cada uma representou uma repetição (calculada pela média de cinco medições ou contagens de diferentes secções).

\section{RESULTADO E DISCUSSÃO}

Os dados referentes à variação no número de estômatos em plântulas de erva-doce, em função dos tratamentos de consórcio e do inseticida estão na Tabela 1. O consórcio, isoladamente, causou influência em todos os órgãos analisados $(p<0,01)$, exceto na face adaxial da folha.

O tratamento 1A2E proporcionou, em média, maior quantidade de estômatos na zona de transição e na face abaxial da folha; o 2A1E foi superior aos demais tratamentos no caule; já a erva-doce solteira apresentou, em média, os melhores resultados no cotilédone. $O$ inseticida causou efeito $(p<0,01)$ no número de estômatos do caule, cotilédone e folhas. $\mathrm{Na}$ face adaxial dos cotilédones, houve aumento de $53 / 10 \mu \mathrm{m}^{2}$ para $59 / 10 \mu \mathrm{m}^{2}$, ao ser aplicado o agrotóxico. Também foi observado efeito da interação em todos os órgãos para o número de estômatos $(p<0,01)$. Nos tratamentos de consórcio que receberam o inseticida, a erva-doce solteira proporcionou os melhores resultados no caule, no cotilédone e na face adaxial da folha; o tratamento $1 \mathrm{~A} 2 \mathrm{E}$ influenciou o número de estômatos na face abaxial da folha; e o 2A1E proporcionou bons resultados na zona de transição. Quando não foi feito o tratamento químico, os consórcios foram melhores; no 1 A2E foram observados $46,75 / 10 \mu m^{2}$ estômatos na zona de transição, $54,5 / 10 \mu m^{2}$ na face adaxial do

TABELA 1. Número de estômatos $/ 10 \mu \mathrm{m}^{2}$ encontrados nos órgãos de plântulas de erva-doce (Foeniculum vulgare Mill.) provenientes de sementes produzidas por plantas consorciadas com algodão colorido cv. Safira, com aplicação do inseticida monocrotofós.

\begin{tabular}{|c|c|c|c|c|c|}
\hline \multicolumn{6}{|c|}{ Consórcios } \\
\hline & Inseticida & $1 \mathrm{~A} 2 \mathrm{E}$ & $2 \mathrm{~A} 1 \mathrm{E}$ & ES & Médias \\
\hline \multirow{4}{*}{$\begin{array}{l}\text { Zona de } \\
\text { transição }\end{array}$} & Com & $30,00 \mathrm{Bb}$ & 39,00Aa & $34,00 \mathrm{ABa}$ & $34,33 a$ \\
\hline & Sem & $46,75 \mathrm{Aa}$ & $24,00 \mathrm{Bb}$ & $25,00 \mathrm{Bb}$ & $31,91 \mathrm{a}$ \\
\hline & Médias & $38,37 \mathrm{~A}$ & $31,50 \mathrm{~B}$ & $29,50 B$ & \\
\hline & $\mathrm{CV}(\%)$ & 10,71 & & & \\
\hline \multirow{4}{*}{ Caule } & Com & $37,75 \mathrm{Ba}$ & $41,50 \mathrm{ABa}$ & $46,00 \mathrm{Aa}$ & $41,75 a$ \\
\hline & Sem & $33,75 \mathrm{Ba}$ & $42,50 \mathrm{Aa}$ & $30,50 \mathrm{Bb}$ & $35,58 b$ \\
\hline & Médias & $35,75 B$ & $42,00 \mathrm{~A}$ & $38,25 \mathrm{AB}$ & \\
\hline & $\mathrm{CV}(\%)$ & 8,96 & & & \\
\hline \multirow{4}{*}{$\begin{array}{c}\text { Cotilédone } \\
\text { abaxial }\end{array}$} & Com & $75,25 \mathrm{Cb}$ & $123,25 \mathrm{Ba}$ & $159,25 \mathrm{Aa}$ & $119,25 a$ \\
\hline & Sem & $98,75 \mathrm{Ba}$ & $123,50 \mathrm{Aa}$ & $122,00 \mathrm{Ab}$ & $114,75 a$ \\
\hline & Médias & $87,00 \mathrm{C}$ & $123,37 \mathrm{~B}$ & $140,62 A$ & \\
\hline & $\mathrm{CV}(\%)$ & 6,23 & & & \\
\hline \multirow{4}{*}{$\begin{array}{c}\text { Cotilédone } \\
\text { adaxial }\end{array}$} & Com & $41,50 \mathrm{Bb}$ & $47,50 \mathrm{Bb}$ & $89,00 \mathrm{Aa}$ & $59,33 a$ \\
\hline & Sem & $54,50 \mathrm{Aa}$ & $54,25 \mathrm{Aa}$ & $50,50 \mathrm{Ab}$ & $53,08 b$ \\
\hline & Médias & $48,00 \mathrm{~B}$ & $50,87 B$ & $69,75 \mathrm{~A}$ & \\
\hline & $\mathrm{CV}(\%)$ & 7,89 & & & \\
\hline \multirow{4}{*}{$\begin{array}{c}\text { Folha } \\
\text { abaxial }\end{array}$} & Com & $156,00 \mathrm{Aa}$ & $142,75 \mathrm{Ba}$ & $140,75 \mathrm{Ba}$ & $146,50 a$ \\
\hline & Sem & $161,75 \mathrm{Aa}$ & $104,00 \mathrm{Bb}$ & $111,25 \mathrm{Bb}$ & $125,66 b$ \\
\hline & Médias & $158,87 \mathrm{~A}$ & $123,37 \mathrm{~B}$ & $126,00 \mathrm{~B}$ & \\
\hline & $\mathrm{CV}(\%)$ & 5,12 & & & \\
\hline \multirow{4}{*}{$\begin{array}{c}\text { Folha } \\
\text { adaxial }\end{array}$} & Com & $76,00 \mathrm{Ba}$ & $83,50 \mathrm{ABa}$ & $91,75 \mathrm{Aa}$ & $83,75 a$ \\
\hline & Sem & $72,25 \mathrm{Aa}$ & $71,75 \mathrm{Ab}$ & $68,00 \mathrm{Ab}$ & $70,66 b$ \\
\hline & Médias & $74,12 \mathrm{~A}$ & $77,62 \mathrm{~A}$ & $79,87 \mathrm{~A}$ & \\
\hline & CV(\%) & 8,44 & & & \\
\hline
\end{tabular}

Médias seguidas pelas mesmas letras (minúsculas nas colunas e maiúsculas nas linhas) não diferem entre si pelo teste de Tukey a $5 \%$ de probabilidade. 1A2E - uma fileira de algodão e duas de erva-doce; 2A1E - duas fileiras de algodão e uma de erva-doce; ES - erva-doce solteira.

Rev. Bras. PI. Med., Botucatu, v.14, n.esp., p.205-213, 2012. 
cotilédone, $161,75 / 10 \mu \mathrm{m}^{2}$ na face abaxial da folha e $72,25 / 10 \mu \mathrm{m}^{2}$ na face adaxial foliar; já no consórcio $2 \mathrm{~A} 1 \mathrm{E}$, os resultados foram superiores apenas no caule e na face abaxial do cotilédone.

As Tabelas 2 e 3 mostram os dados referentes aos diâmetros polar e equatorial dos estômatos presentes em plântulas de erva-doce provenientes de sementes produzidas em sistemas consorciados e com aplicação de inseticida.

O inseticida não causou influência no diâmetro polar dos estômatos em nenhum órgão, e no equatorial, apenas no caule $(1,56 \mu \mathrm{m})(p<0,01) \mathrm{e}$ na face adaxial da folha $(1,90 \mu \mathrm{m})(p<0,05)$, quando comparado à testemunha $(1,73 \mu \mathrm{m}$ e $2,12 \mu \mathrm{m}$, respectivamente). Em contrapartida, o consórcio influenciou o diâmetro polar dos estômatos da zona de transição $(p<0,05)$, caule $(p<0,01)$ e faces adaxiais do cotilédone $(p<0,05)$ e da folha $(p<0,01)$ e o diâmetro equatorial do caule $(p<0,01)$ e da face adaxial cotiledonar $(p<0,01)$. Os consórcios que apresentaram os melhores resultados para o diâmetro polar foram 2A1E para as faces adaxiais do cotilédone $(4,27 \mu \mathrm{m})$ (Figura
1) e da folha $(4,14 \mu \mathrm{m})$ (Figura 2) e ES para a zona de transição $(5,10 \mu \mathrm{m})$ (Figuras 3a, b e c) e o caule $(3,02$ $\mu \mathrm{m}$ ) (Figuras 3d, e e f). No diâmetro equatorial, houve efeito positivo do $1 \mathrm{~A} 2 \mathrm{E}$ para o caule $(1,83 \mu \mathrm{m})$ (Figuras $3 a, b$ e c) e 2A1E para a face adaxial do cotilédone $(2,40 \mu \mathrm{m})$ (Figura 1).

A interação entre os dois fatores foi significativa para o diâmetro polar dos estomatos do caule $(p<0,01)$, do cotilédone adaxial $(p<0,05)$ e da folha abaxial $(p<0,01)$ e para o diâmetro equatorial do caule $(p<0,01)$, da face abaxial do cotilédone $(p<0,05)$ e da face adaxial da folha $(p<0,01)$. Quando houve aplicação de inseticida, observou-se os melhores resultados do diâmetro polar dos estômatos no ES para o caule $(3,50 \mu \mathrm{m})$ e no $2 \mathrm{~A} 1 \mathrm{E}$ para a face adaxial do cotilédone $(4,42 \mu \mathrm{m})$; já quando houve aplicação química, obtiveram-se os melhores resultados nos consórcios $1 \mathrm{~A} 2 \mathrm{E}$ para o caule $(3,55 \mu \mathrm{m})$ e da ervadoce solteira para folha abaxial $(3,12 \mu \mathrm{m})$. Com tratamento químico, o diâmetro equatorial dos estômatos recebeu influência positiva da ES (1,62 $\mu \mathrm{m})$ e do $2 \mathrm{~A} 1 \mathrm{E}(2,15 \mu \mathrm{m})$.

TABELA 2. Diâmetro polar $(\mu \mathrm{m})$ dos estômatos encontrados nos órgãos de plântulas de erva-doce (Foeniculum vulgare Mill.) provenientes de sementes produzidas por plantas consorciadas com algodão colorido cv. Safira, com aplicação do inseticida monocrotofós.

\begin{tabular}{|c|c|c|c|c|c|}
\hline \multicolumn{6}{|c|}{ Consórcios } \\
\hline & Inseticida & $1 \mathrm{~A} 2 \mathrm{E}$ & $2 \mathrm{~A} 1 \mathrm{E}$ & ES & Médias \\
\hline \multirow{4}{*}{$\begin{array}{l}\text { Zona de } \\
\text { transição }\end{array}$} & Com & 4,37 & 4,87 & 5,37 & $4,87 a$ \\
\hline & Sem & 4,42 & 4,65 & 4,82 & $4,63 a$ \\
\hline & Médias & $4,40 B$ & $4,76 \mathrm{AB}$ & $5,10 \mathrm{~A}$ & \\
\hline & $\mathrm{CV}(\%)$ & 9,52 & & & \\
\hline \multirow{4}{*}{ Caule } & Com & $2,92 \mathrm{Bb}$ & $2,42 \mathrm{Ba}$ & $3,50 \mathrm{Aa}$ & $2,95 a$ \\
\hline & Sem & $3,55 \mathrm{Aa}$ & $2,82 \mathrm{Ba}$ & $2,55 \mathrm{Bb}$ & $2,97 a$ \\
\hline & Médias & $3,23 \mathrm{~A}$ & $2,62 B$ & $3,02 \mathrm{~A}$ & \\
\hline & CV $(\%)$ & 9,75 & & & \\
\hline \multirow{4}{*}{$\begin{array}{c}\text { Cotilédone } \\
\text { abaxial }\end{array}$} & Com & 4,10 & 3,52 & 4,15 & $3,92 a$ \\
\hline & Sem & 3,77 & 3,90 & 4,10 & $3,92 a$ \\
\hline & Médias & $3,93 \mathrm{~A}$ & $3,71 \mathrm{~A}$ & $4,12 \mathrm{~A}$ & \\
\hline & CV $(\%)$ & 11,27 & & & \\
\hline \multirow{4}{*}{$\begin{array}{c}\text { Cotilédone } \\
\text { adaxial }\end{array}$} & Com & $3,62 \mathrm{Ba}$ & $4,42 \mathrm{Aa}$ & $4,00 \mathrm{ABa}$ & $4,01 \mathrm{a}$ \\
\hline & Sem & 4,17Aa & $4,12 \mathrm{ABa}$ & $3,47 \mathrm{Ba}$ & $3,92 a$ \\
\hline & Médias & $3,90 \mathrm{AB}$ & $4,27 \mathrm{~A}$ & $3,73 B$ & \\
\hline & CV $(\%)$ & 9,74 & & & \\
\hline \multirow{4}{*}{$\begin{array}{l}\text { Folha } \\
\text { abaxial }\end{array}$} & Com & $2,55 \mathrm{Aa}$ & 3,32Aa & $2,87 \mathrm{Aa}$ & $2,91 \mathrm{a}$ \\
\hline & Sem & $2,90 \mathrm{ABa}$ & $2,17 \mathrm{Bb}$ & $3,12 \mathrm{Aa}$ & $2,73 a$ \\
\hline & Médias & $2,72 \mathrm{~A}$ & $2,75 \mathrm{~A}$ & $3,00 \mathrm{~A}$ & \\
\hline & CV(\%) & 16,22 & & & \\
\hline \multirow{4}{*}{$\begin{array}{l}\text { Folha } \\
\text { adaxial }\end{array}$} & Com & 2,33 & 4,01 & 2,83 & $3,05 a$ \\
\hline & Sem & 2,75 & 4,28 & 3,21 & $3,41 \mathrm{a}$ \\
\hline & Médias & $2,54 \mathrm{~B}$ & $4,14 \mathrm{~A}$ & $3,02 B$ & \\
\hline & CV $(\%)$ & 13,82 & & & \\
\hline
\end{tabular}

Médias seguidas pelas mesmas letras (minúsculas nas colunas e maiúsculas nas linhas) não diferem entre si pelo teste de Tukey a $5 \%$ de probabilidade. 1A2E - uma fileira de algodão e duas de erva-doce; 2A1E - duas fileiras de algodão e uma de erva-doce; ES - erva-doce solteira. 
TABELA 3. Diâmetro equatorial $(\mu \mathrm{m})$ dos estômatos encontrados nos órgãos de plântulas de erva-doce (Foeniculum vulgare Mill.) provenientes de sementes produzidas por plantas consorciadas com algodão colorido cv. Safira, com aplicação do inseticida monocrotofós.

\begin{tabular}{|c|c|c|c|c|c|}
\hline \multicolumn{6}{|c|}{ Consórcios } \\
\hline & Inseticida & $1 \mathrm{~A} 2 \mathrm{E}$ & 2A1E & ES & Médias \\
\hline \multirow[t]{4}{*}{ Zona de transição } & Com & 2,05 & 2,02 & 2,30 & 2,12 \\
\hline & Sem & 2,15 & 2,22 & 2,00 & 2,12 \\
\hline & Médias & 2,10 & 2,12 & 2,15 & \\
\hline & $\mathrm{CV}(\%)$ & 8,55 & & & \\
\hline \multirow[t]{4}{*}{ Caule } & Com & $1,75 \mathrm{Ab}$ & $1,32 \mathrm{Bb}$ & $1,62 \mathrm{Aa}$ & $1,56 b$ \\
\hline & Sem & $1,92 \mathrm{Aa}$ & $1,75 \mathrm{Aa}$ & $1,52 \mathrm{Ba}$ & $1,73 a$ \\
\hline & Médias & $1,83 \mathrm{~A}$ & $1,53 \mathrm{~B}$ & $1,57 \mathrm{~B}$ & \\
\hline & CV $(\%)$ & 6,54 & & & \\
\hline \multirow[t]{4}{*}{ Cotilédone abaxial } & Com & $2,40 \mathrm{Aa}$ & $2,20 \mathrm{Aa}$ & $2,27 \mathrm{Aa}$ & $2,29 a$ \\
\hline & Sem & $2,00 \mathrm{Bb}$ & $2,35 \mathrm{ABa}$ & $2,40 \mathrm{Aa}$ & $2,25 a$ \\
\hline & Médias & $2,20 \mathrm{~A}$ & $2,27 \mathrm{~A}$ & $2,33 \mathrm{~A}$ & \\
\hline & CV $(\%)$ & 8,91 & & & \\
\hline \multirow[t]{4}{*}{ Cotilédone adaxial } & Com & 1,95 & 2,35 & 2,25 & $2,18 a$ \\
\hline & Sem & 2,12 & 2,45 & 2,30 & $2,29 a$ \\
\hline & Médias & $2,03 B$ & $2,40 \mathrm{~A}$ & $2,27 A B$ & \\
\hline & CV $(\%)$ & 8,47 & & & \\
\hline \multirow[t]{4}{*}{ Folha abaxial } & Com & 1,95 & 2,10 & 1,72 & $1,92 a$ \\
\hline & Sem & 2,12 & 1,87 & 1,90 & $1,96 a$ \\
\hline & Médias & $2,03 \mathrm{~A}$ & $1,98 \mathrm{~A}$ & $1,81 \mathrm{~A}$ & \\
\hline & CV $(\%)$ & 11,82 & & & \\
\hline \multirow[t]{4}{*}{ Folha adaxial } & Com & $1,82 \mathrm{ABb}$ & $2,15 \mathrm{Aa}$ & $1,74 \mathrm{Bb}$ & $1,90 b$ \\
\hline & Sem & $2,35 \mathrm{Aa}$ & $1,92 \mathrm{Ba}$ & $2,10 \mathrm{ABa}$ & $2,12 a$ \\
\hline & Médias & $2,08 \mathrm{~A}$ & $2,03 \mathrm{~A}$ & $1,92 \mathrm{~A}$ & \\
\hline & $\mathrm{CV}(\%)$ & 10,53 & & & \\
\hline
\end{tabular}

Médias seguidas pelas mesmas letras (minúsculas nas colunas e maiúsculas nas linhas) não diferem entre si pelo teste de Tukey a $5 \%$ de probabilidade. 1A2E - uma fileira de algodão e duas de erva-doce; $2 \mathrm{~A} 1 \mathrm{E}$ - duas fileiras de algodão e uma de erva-doce; ES - erva-doce solteira.

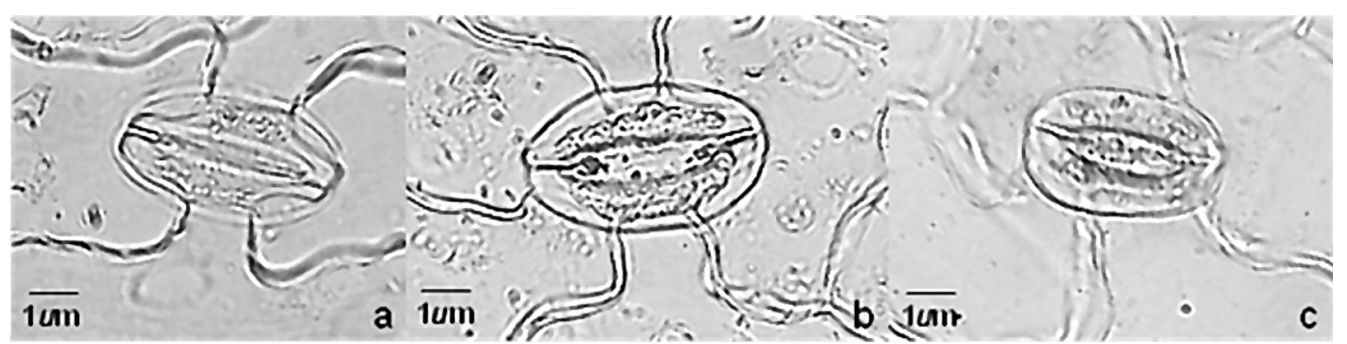

FIGURA 1. Diâmetro polar e equatorial dos estômatos da face adaxial cotiledonar da plântula de Foeniculum vulgare Mill. em função dos consórcios. a. 1A2E. b. 2A1E. c. ES.

Estômatos são estruturas importantes para a produção vegetal, pois representam a porta de entrada e de escoamento dos gases para a fotossíntese, processo primordial relacionado à produtividade vegetal (Silva et al., 2004). Além disso, são os principais responsáveis pela transpiração e por isso, estão intimamente ligados ao ambiente, controlando a perda de água (Cutter, 1986; Fanh, 1990), ao mesmo tempo em que permitem absorção suficiente de $\mathrm{CO}_{2}$ para a fotossíntese (Taiz \& Zeiger, 2009).
Cutter (1986) relata que têm sido realizadas diversas experiências com o empenho de descobrir os fatores que controlam a formação e a distribuição dos estômatos. Vários autores já concluíram que modificações na quantidade e no tamanho dos estômatos são influenciadas pelo estado nutricional do vegetal (Santana et al., 2008), quantidade de água disponível (Kolb et al., 1998; Justo et al., 2005), intensidade luminosa (Santiago et al., 2001; Nery et al., 2007; Costa et al., 2007), compostos químicos 


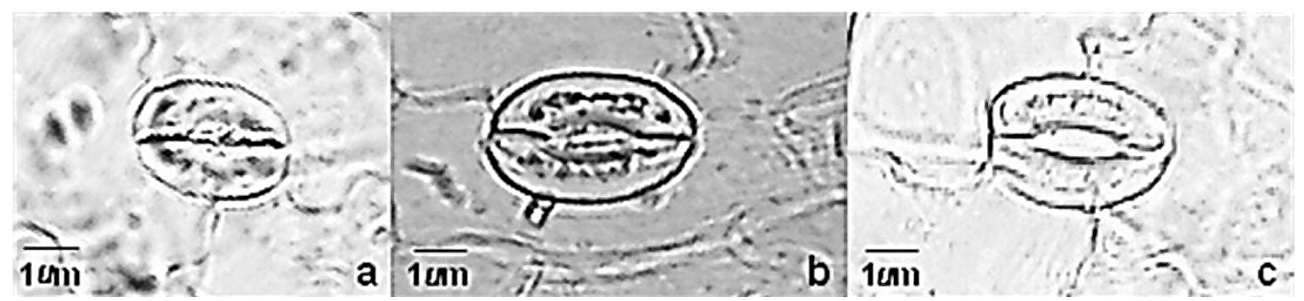

FIGURA 2. Diâmetro polar dos estômatos da face adaxial foliar da plântula de Foeniculum vulgare Mill. em função dos sistemas de consórcio. a. 1A2E. b. 2A1E. c. ES.

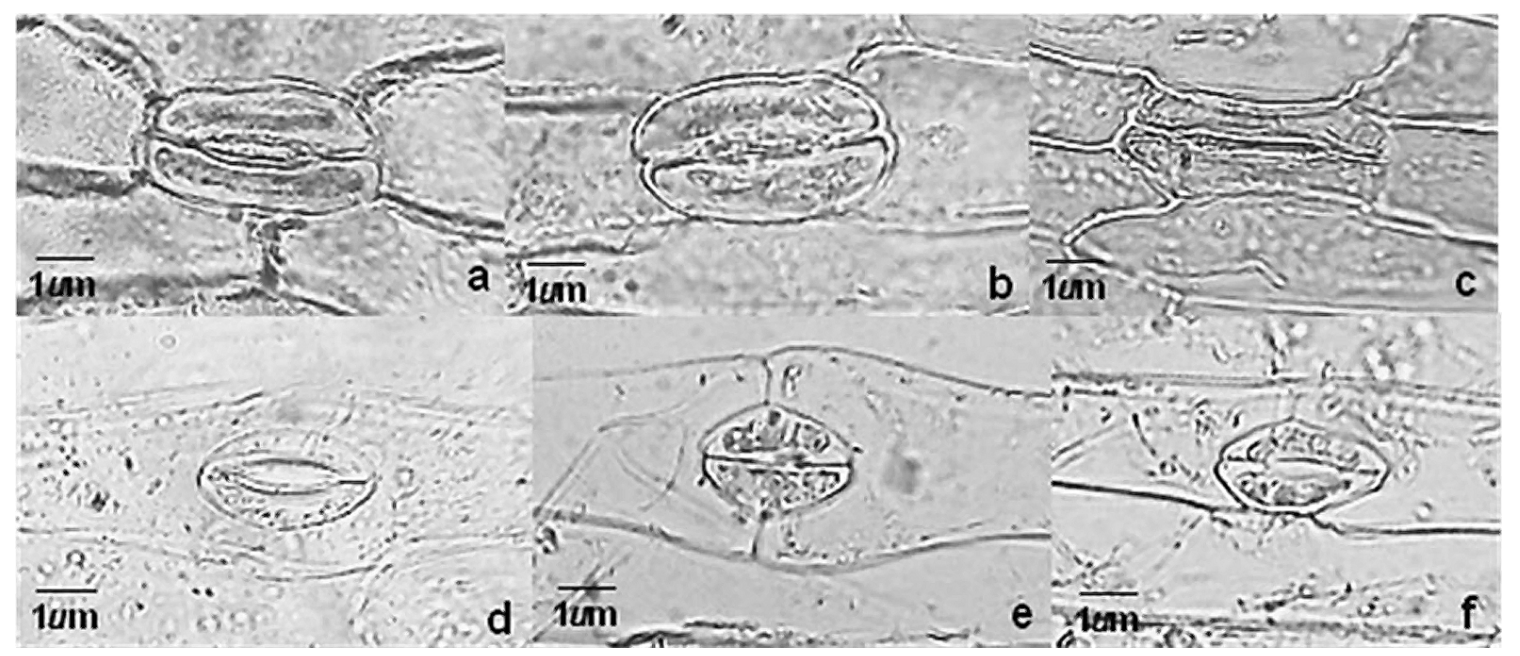

FIGURA 3. Diâmetro polar dos estômatos da zona de transição e do caule da plântula de Foeniculum vulgare Mill. em função dos sistemas de consórcio. a. 1A2E - zona de transição. b. 2A1E - zona de transição. c. ES - zona de transição. d. 1A2E - caule. e. 2A1E - caule. f. ES - caule.

(Dickison, 2000) e grau de ploidia da planta (Cutter, 1986).

De forma geral, os consórcios proporcionaram maior desenvolvimento dos diâmetros polar e equatorial dos estômatos no caule e nas faces adaxiais dos cotilédones e das folhas, aumentando a transpiração nesses órgãos, pois Justo et al. (2005) explicam que folhas com estômatos menores apresentam maior eficiência de uso da água e a diferença no tamanho da abertura estomática apresenta maior efeito sobre a difusão de água do que sobre a de $\mathrm{CO}_{2}$.

$\mathrm{Na}$ erva-doce, o agrotóxico causou diminuição no diâmetro equatorial dos estômatos presentes na face adaxial da folha, porém aumentou a quantidade. Em contrapartida, Martins \& Castro (1999) observaram pequeno aumento no tamanho dos estômatos na epiderme abaxial aos 20 dias após o tratamento com regulador vegetal SADH (ácido succínico-2,2-dimetilhidrazida).

O aumento no número de estômatos na folha e no cotilédone, observados quando houve aplicação do inseticida contrastam com os resultados obtidos por Martins \& Castro (1999), que observaram diminuição do número de estômatos da folha ao ser feita aplicação de SADH (ácido succínico-2,2-dimetilhidrazida) diretamente na planta adulta; porém, os mesmos autores obtiveram resultados positivos no mesmo órgão, ao adicionar CCC (chlormequat 2-cloretoetil trimetilamônio).

Essas modificações morfológicas estão associadas com funções específicas. A impermeabilidade da cutícula à água faz com que a maior parte da transpiração foliar resulte da difusão de vapor de água através dos poros estomáticos, que reduzem a perda de água (Taiz \& Zeiger, 2009). Dessa forma, os tratamentos em que a quantidade de estômatos foi maior, principalmente nos cotilédones e nas folhas, proporcionam maior controle da transpiração. Castro (2002) explica ainda, que o aumento no número de estômatos por área pode permitir que a planta aumente a condutância de gases e, assim, evitar que a fotossíntese seja limitada sob diferentes condições de ambiente. De acordo com 
Taiz \& Zeiger (2009), as mudanças na resistência estomática, exercida pelas células-guarda que circundam o poro estomático, são importantes para a regulação da perda de água pela planta e para o controle da taxa de absorção de dióxido de carbono necessária à fixação continuada de $\mathrm{CO}_{2}$ durante a fotossíntese.

As contagens do número de cloroplastos presentes nas células-guarda dos estômatos do cotilédone e da folha (Tabela 4) evidenciaram o efeito significativo $(p<0,01)$ dos consórcios, do inseticida e da interação entre esses dois fatores nos dois órgãos.

Isoladamente, o inseticida exerceu influência positiva nas faces abaxial e adaxial do cotilédone $\left(32,6 / 10 \mu \mathrm{m}^{2}\right.$ e $\left.38,1 / 10 \mu \mathrm{m}^{2}\right)$ e da folha $\left(33,2 / 10 \mu \mathrm{m}^{2}\right.$ e $\left.40,3 / 10 \mu \mathrm{m}^{2}\right)$, quando comparada aos tratamentos que não receberam o agrotóxico (cotilédone - 22,4/10 $\mu \mathrm{m}^{2}$ e 17,9/10 $\mu \mathrm{m}^{2}$ e folha/10 $\mu \mathrm{m}^{2}-28,5$ e $\left.24,9 / 10 \mu \mathrm{m}^{2}\right)$. Os consórcios 2A1E para as faces abaxial $\left(40,2 / 10 \mu \mathrm{m}^{2}\right)$ e adaxial $(35,9 /$ $10 \mu \mathrm{m}^{2}$ ) foliares, e $1 \mathrm{~A} 2 \mathrm{E}$ para as faces abaxial $\left(34,6 / 10 \mu \mathrm{m}^{2}\right)$ e adaxial $\left(33,3 / 10 \mu \mathrm{m}^{2}\right)$ cotiledonares, proporcionaram os maiores resultados.

A interação entre os consórcios e o inseticida foi significativa apenas quando não houve aplicação de inseticida. Na epiderme abaxial, os estômatos que apresentaram maior quantidade de cloroplastos foram os provenientes da ES $(14,5 /$ $10 \mu \mathrm{m}^{2}$ ); na folha o consórcio 2A1E proporcionou resultados superiores tanto na face abaxial $(41,2 /$ $\left.10 \mu \mathrm{m}^{2}\right)$, como na adaxial $\left(36,2 / 10 \mu \mathrm{m}^{2}\right)$.

Nos órgãos fotossintetizantes tais como as folhas, caules jovens e cotilédones, as células epidérmicas são normalmente destituídas de cloroplastos completamente desenvolvidos, exceto para as células-guarda dos estômatos (Cutter, 1986). A biossíntese de clorofila e o desenvolvimento de cloroplastos em plantas superiores envolvem claramente uma série de eventos correlacionados, dentre eles, vários fatores podem influenciar essa formação, como a intensidade de luz, fatores nutricionais (Lima Júnior et al., 2005) e agentes químicos aplicados exoneramente (Wolf, 1977).

A maior disponibilidade de nutrientes, luz solar e água dos sistemas consorciados durante a produção das sementes (Rezende et al., 2001), podem ter causado o aumento na produção de cloroplastos nas plântulas provenientes de sementes produzidas em consórcio, devido à transferência dessa característica à geração seguinte.

As plântulas de erva-doce apresentaram aumento do número de cloroplastos nas célulasguarda dos estômatos quando houve tratamento químico. Fato comprovado por Dickison (2000), que explica que as plantas tratadas com inseticidas apresentam mesofilo foliar mais compacto, além de número bem maior de cloroplastos. Para Costa et al. (2007) esse é um mecanismo que garante

TABELA 4. Número de cloroplastos $/ 10 \mu \mathrm{m}^{2}$ presentes nas células-guarda dos estômatos do cotilédone e da folha de plântulas de erva-doce (Foeniculum vulgare Mill.) provenientes de sementes produzidas por plantas consorciadas com algodão colorido cv. Safira, com aplicação do inseticida monocrotofós.

\begin{tabular}{|c|c|c|c|c|c|}
\hline \multicolumn{6}{|c|}{ Consórcios } \\
\hline & Inseticida & 1A2E & $2 \mathrm{~A} 1 \mathrm{E}$ & ES & Médias \\
\hline \multirow{4}{*}{$\begin{array}{c}\text { Cotilédone } \\
\text { abaxial }\end{array}$} & Com & $44,5 \mathrm{Aa}$ & $36,0 \mathrm{Ba}$ & $17,5 \mathrm{Ca}$ & $32,6 a$ \\
\hline & Sem & $24,7 \mathrm{Ab}$ & $28,0 \mathrm{Ab}$ & $14,5 \mathrm{Ba}$ & $22,4 b$ \\
\hline & Médias & $34,6 \mathrm{~A}$ & $32,0 \mathrm{~A}$ & $16,0 \mathrm{~B}$ & \\
\hline & CV(\%) & 12,03 & & & \\
\hline \multirow{4}{*}{$\begin{array}{c}\text { Cotilédone } \\
\text { adaxial }\end{array}$} & Com & $45,7 \mathrm{Aa}$ & $33,7 \mathrm{Ba}$ & $35,0 \mathrm{Ba}$ & $38,1 a$ \\
\hline & Sem & $21,0 \mathrm{Ab}$ & $22,2 \mathrm{Ab}$ & $10,5 \mathrm{Bb}$ & $17,9 b$ \\
\hline & Médias & $33,3 \mathrm{~A}$ & $28,0 \mathrm{AB}$ & $22,7 \mathrm{~B}$ & \\
\hline & CV $(\%)$ & 15,66 & & & \\
\hline \multirow{4}{*}{$\begin{array}{l}\text { Folha } \\
\text { abaxial }\end{array}$} & Com & $37,5 \mathrm{Aa}$ & $39,2 \mathrm{Aa}$ & $23,0 \mathrm{Ba}$ & $33,2 a$ \\
\hline & Sem & $25,0 \mathrm{Bb}$ & $41,2 \mathrm{Aa}$ & $19,2 \mathrm{Cb}$ & $28,5 b$ \\
\hline & Médias & $31,2 \mathrm{~B}$ & $40,2 \mathrm{~A}$ & $21,1 \mathrm{C}$ & \\
\hline & $\mathrm{CV}(\%)$ & 8,05 & & & \\
\hline \multirow{4}{*}{$\begin{array}{c}\text { Folh } \\
\text { adaxial }\end{array}$} & Com & $37,5 \mathrm{Ba}$ & $35,7 \mathrm{Ba}$ & $47,7 \mathrm{Aa}$ & $40,3 a$ \\
\hline & Sem & $22,7 \mathrm{Bb}$ & $36,2 \mathrm{Aa}$ & $16,0 \mathrm{Bb}$ & $24,9 b$ \\
\hline & Médias & $30,1 \mathrm{~B}$ & $35,9 \mathrm{~A}$ & $31,85 \mathrm{AB}$ & \\
\hline & $\mathrm{CV}(\%)$ & 13,58 & & & \\
\hline
\end{tabular}

Médias seguidas pelas mesmas letras (minúsculas nas colunas e maiúsculas nas linhas) não diferem entre si pelo teste de Tukey a $5 \%$ de probabilidade. 1A2E - uma fileira de algodão e duas de erva-doce; 2A1E - duas fileiras de algodão e uma de erva-doce; ES - erva-doce solteira.

Rev. Bras. PI. Med., Botucatu, v.14, n.esp., p.205-213, 2012. 
sobrevivência das plantas de forma mais eficiente. Em contrapartida, Santos et al. (2005) observaram redução da clorofila em folhas de eucalipto submetido a tratamento com o herbicida Glyphosate, demonstrando os efeitos tóxicos desse produto.

O número e o tamanho dos estômatos dos cotilédones e das folhas, bem como, a quantidade de cloroplastos presentes nas células-guarda, foram favorecidos pelo consórcio com algodão cv. BRS Safira e pela utilização de inseticida.

\section{AGRADECIMENTO}

Ao CNPq e à FINEP pelo apoio financeiro.

\section{REFERÊNCIA}

ALTIERI, M.A. Agroecologia: a dinâmica produtiva da agricultura sustentável. 2.ed. Porto Alegre: Editora Universidade/UFRGS, 2000. 110p.

AZEVEDO, C.F.; BRUNO, R.L.A.; QUIRINO, Z.G.M. Sistemas agroecológicos com uso de agrotóxico na produção de sementes de erva-doce. In: SEABRA, G.F.; MENDONÇA, I.T.L. (Orgs.). Educação Ambiental para a Sociedade Sustentável e Saúde Global. João Pessoa: Editora Universitária da UFPB, 2009, p.476-83.

BREDEMEIER, C.; MUNDSTOCK, C.M.; BUTTENBENDER, D. Efeito do tamanho das sementes de trigo no desenvolvimento inicial das plantas e no rendimento de grãos. Pesquisa Agropecuária Brasileira, v.36, n.8, p.1061-8, 2001.

CASTRO, E.M. Alterações anatômicas, fisiológicas e fitoquímicas em plantas de Mikania glomerata Sprengel (guaco) sob diferentes fotoperíodos e níveis de sombreamento. 2002. 221p. Tese (Doutorado em Fitotecnia) - Universidade Federal de Lavras, Lavras.

CASTRO, I.M. et al. Efeitos de tratamentos diferenciados no plantio de banana var. Prata-Anã através da quantificação de resíduos de carbofuran. Revista Brasileira de Fruticultura, v.27, n.1, p.40-2, 2005.

CEOLIN, G.B.; RUCKER, A.; KRAY, J.G. Análise epidérmica foliar na diferenciação de plântulas de Geonoma schottiana e Euterpe edulis (Arecaceae). Revista Brasileira de Biociências, v.5, p.18-20, 2007.

CHABOUSSOU, F. Plantas doentes pelo uso de agrotóxicos. 1. ed. São Paulo: Expressão Popular, 2006. $320 \mathrm{p}$.

COSTA, L.C.B. et al. Aspectos da anatomia foliar de Ocimum selloi Benth. (Lamiaceae) em diferentes condições de qualidade de luz. Revista Brasileira de Biociências, v.5, p.6-8, 2007.

CRESTANA, C.M.; BELTRATI, C.M. Morfologia e anatomia das sementes de Copaifera langsdorffii Desf. (Leguminosae-Caesalpinioideae). Naturalia, v.13, p.4554, 1988.

CUTTER, E.G. Anatomia vegetal - parte I: células e tecidos. 2.ed. São Paulo: Roca, 1986. 304p.

DICKISON, W.C. Integrative plant anatomy. San Diego: Harcourt/Academic Press, 2000. 533p.

FAHN, A. Plant anatomy. 4.ed. Oxford: Pergamon Press,
1990. 588p.

GLIESSMAN, S.R. Agroecologia: processos ecológicos em agricultura sustentável. Porto Alegre: Ed. Universidade/UFRGS, 2001. 653p.

JUSTO, C.F. et al. Plasticidade anatômica das folhas de Xylopia brasiliensis Sprengel (Annonaceae). Acta Botânica Brasílica, v.19, n.1, p.112-23, 2005.

KOLB, R.M. et al. Anatomia ecológica de Sebastiania commersoniana (Baillon) Smith \& Downs (Euphorbiaceae) submetida ao alagamento. Revista Brasileira de Botânica, v.21, n.3, p.305-12, 1998.

LEAL-COSTA, M.V. et al. Anatomia foliar de plantas transgênicas e não transgênicas de Glycine max (L.) Merrill (Fabaceae). Revista Brasileira de Biociências, v.14, n.1, p.23-31, 2008.

LIMA; F.S. et al. Épocas relativas de plantio e adubação nitrogenada: índices agroeconômicos do algodoeiro consorciado com gergelim. Revista Ciência Agronômica, v. 39, n. 4, p.555-61, 2008.

LIMA JÚNIOR, E.C. et al. Trocas gasosas, características das folhas e crescimento de plantas jovens de Cupania vernalis Camb. submetidas a diferentes níveis de sombreamento. Ciência Rural, v.35, n.5, p.1092-7, 2005. LIRA, R.S.; BATISTA, J.L. Aspectos biológicos de Chrysoperla externa alimentados com pulgões da ervadoce. Revista de Biologia e Ciências da Terra, v.6, n.2, p.20-35, 2006.

MARTINS, M.B.G.; CASTRO, P.R.C. Reguladores vegetais e a anatomia da folha de tomate (Lycopersicon esculentum Mill.) cv. Ângela Gigante. Scientia Agrícola, v.56, n.3, p.693-703, 1999.

MODESTO, J.C.; RODRIGUES, J.D.; PINHO, S.Z. Efeito do ácido giberélico sobre o comprimento e diâmetro do caule de plântulas de limão cravo (Citrus limonia Osbeck). Scientia Agrícola, v.53, n.2-3, p.332-7, 1996. MORAES-DALLAQUA, M.A.; BELTRATI, C.M.; RODRIGUES, J.D. Anatomia de ápices radiculares de feijão cv. carioca submetidos a níveis de boro em solução nutritiva. Scientia Agrícola, v.57, n.3, p.425-30, 2000.

NEGRISOLI, E. et al. Seletividade de herbicidas aplicados em pré-emergência na cultura de cana-deaçúcar tratada com nematicidas. Planta Daninha, v.22, n.4, p.567-75, 2004.

NERY, F.C. et al. Aspectos anatômicos de folhas de plantas jovens de Calophyllum brasiliense Cambess. submetidas a diferentes níveis de sombreamento. Revista Brasileira de Biociências, v.5, p.129-31, 2007. NUNES, M.U.C. et al. Introdução de tecnologias agroecológicas no sistema de produção de erva-doce em Sergipe. Revista Brasileira de Agroecologia, v.2, n.2, p.743-6, 2007.

REZENDE, P.M. et al. Consórcio sorgo-soja. v. comportamento de híbridos de sorgo e cultivares de soja consorciados na entrelinha no rendimento de forragem. Ciência Rural, v.31, n.3, p.369-74, 2001.

SANTANA, J.R.F. et al. Estímulo do comportamento fotoautotrófico durante o enraizamento in vitro de Annona glabra L. Aspectos da anatomia da folha antes da aclimatização. Ciência agrotécnica, v.32, n.2, p.640-4, 2008. SANTIAGO, E.J.A. et al. Aspectos da anatomia foliar da pimenta-longa (Piper hispidinervium C. DC.) sob diferentes condições de luminosidade. Ciência agrotécnica, v.25, n.5, p.1035-42, 2001. 
SANTOS, L.D.T. et al. Crescimento e morfoanatomia foliar de eucalipto sob efeito de deriva do glyphosate. Planta daninha, v.23, n.1, p.133-42, 2005.

SILVA, L.M.; ALQUINI, Y.; CAVALLET, V.J. Inter-relações entre a anatomia vegetal e a produção vegetal. Revista Brasileira de Biociências, v.5, p.120-2, 2004.

WOLF, F.T. Effects os chemical agents in innibition of chlorophyl syntesis and chloroplast development in higher plants. The Botanical Riview, v.43, n.4, p.395-425, 1977.

SILVA, M.N.B. et al. Consórcio do algodoeiro colorido BRS-200 com feijão macassar sob manejo orgânico. Campina Grande: EMBRAPA, 2007. 20p. 